\title{
Association of Pseudoexfoliation (PXF) with Glaucoma and Climate Droplet Keratopathy (CDK)
}

\author{
Dr. Chandra Kanth ${ }^{1}$, Dr. Sfoorti Goswami ${ }^{1}$, Dr. Visalakshi Subramanian ${ }^{1}$, Dr. \\ Sudha Jeyaram ${ }^{1}$, Dr. Naishadh Jivrajani ${ }^{1}$, Dr. Vijay Bhaskar Gajjala ${ }^{1}$ \\ (' Department of Ophthalmology, Sankara Eye Hospital, Krishnankoil-626190, Tamil Nadu, India)
}

\begin{abstract}
:
Purpose: To find out correlation of Pseudoexfoliation (PXF) with glaucoma and Climatic droplet keratopathy (CDK).

Setting: Department of Ophthalmology, Sankara Eye Hospital, Krishnankovil, Tamil Nadu.

Study design: An observational clinical study

Patients and Methods: 50 patients with Pseudoexfoliation (PXF) and 50 patients without Pseudoexfoliation

$(P X F)$ were studied and analyzed for glaucoma and Climatic Droplet keratopathy $(C D K)$.

Results: PXF is strongly associated with glaucoma and significantly associated with Climatic Droplet

Keratopathy.

Conclusion: Glaucomatous optic neuropathy and CDK occur more frequently in the population with PXF syndrome compared to people without PXF.
\end{abstract}

Keywords: Angle closure Glaucoma, Climatic Droplet Keratopathy, Occludable angles, Ocular Hypertension, Pseudoexfoliation.

\section{Introduction}

Exfoliation syndrome is the most common identifiable cause of open-angle glaucoma worldwide (1). It is a systemic disorder with important eye manifestations, including development of open and closed angle glaucoma and of cataract with zonular instability (2). It may also be associated with increased systemic risk of cardiovascular disorders (3). It is a generalised disorder of the extracellular matrix, characterised by the production of abnormal basement membrane-like material in several intraocular and extraocular tissues.

Exfoliative material may also be seen as white flecks on the pupillary margin of the iris, with loss of pigment at the pupillary ruff (4). Iris transillumination typically reveals a moth-eaten pattern near the pupillary sphincter, and many patients also have diffuse midperipheral transillumination defects $(4,5)$.

Associated anatomical features include pupillary ruff atrophy, pigment dispersion, elevated intraocular pressures with or without glaucoma (6). It is reported to be a risk factor for narrow angle and angle closure glaucoma (ACG) $(7,8)$.

As per best of our knowledge, there is no study on the association between PXF with CDK from the Indian subcontinent. In this study, we report the association between PXF with Glaucoma and CDK in a rural population in southern India.

\section{Materials \& Methods}

This is an observational clinical study. Patients visited to our hospital from $1^{\text {st }}$ JAN 2014 to $31^{\text {st }}$ MARCH 2016. The study was carried out after approval by the institutional review board. Written informed consent was taken from all participants before the commencement of examination. Their complete medical records were studied and analyzed.

\subsection{Aim:}

1) To find out correlation of PXF with GLAUCOMA.

2) To find out correlation of PXF with CDK.

\subsection{Eligibility criteria}

Those aged 50 years and above or those turning 50 in the current calendar year.

\subsection{Statistical Methods:}

Descriptive and inferential statistical analysis has been carried out in the present study. Results on continuous measurements are presented on Mean \pm SD (Min-Max) and results on categorical measurements are 
presented in Number (\%). Significance is assessed at $5 \%$ level of significance. The following assumptions on data are made,

Assumptions: 1.Dependent variables should be normally distributed, 2.Samples drawn from the population should be random, cases of the samples should be independent. Student t test (two tailed, independent) has been used to find the significance of study parameters on continuous scale between two groups (Inter group analysis) on metric parameters.

Chi-square/ Fisher Exact test has been used to find the significance of study parameters on categorical scale between two or more groups. Significant figures

+ Suggestive significance $(\mathrm{P}$ value: $0.05<\mathrm{P}<0.10)$

* Moderately significant ( $\mathrm{P}$ value: $0.01<\mathrm{P} \leq 0.05)$, ** Strongly significant $(\mathrm{P}$ value: $\mathrm{P} \leq 0.01)$

Statistical software: The Statistical software namely SAS 9.2, SPSS 15.0, Stata 10.1, MedCalc 9.0.1 ,Systat 12.0 and R environment ver.2.11.1 were used for the analysis of the data and Microsoft word and Excel have been used to generate graphs, tables etc.

\section{Results}

Study design: An observational clinical study

Table 1: Age distribution of patients studied

\begin{tabular}{|l|l|l|l|l|}
\hline \multirow{2}{*}{ Age in years } & Cases & \multicolumn{4}{l|}{ Control } \\
\cline { 2 - 6 } & No & $\%$ & No & $\%$ \\
\hline $50-60$ & 11 & 22.0 & 22 & 44.0 \\
\hline $61-70$ & 23 & 46.0 & 19 & 38.0 \\
\hline $71-80$ & 15 & 30.0 & 8 & 16.0 \\
\hline$>80$ & 1 & 2.0 & 1 & 2.0 \\
\hline Total & 50 & 100.0 & 50 & 100.0 \\
\hline Mean \pm SD & $66.86 \pm 7.28$ & $63.54 \pm 7.45$ & \\
\hline
\end{tabular}

In the above table, $\mathrm{P}=0.026^{*}$, Significant, Student $\mathrm{t}$ test. PXF is significantly associated with increase in age.

Table 2: Gender distribution of patients studied

\begin{tabular}{|l|l|l|l|l|}
\hline \multirow{2}{*}{ Gender } & Cases & $\%$ & Control \\
\cline { 2 - 5 } & No & 32.0 & No & $\%$ \\
\hline Female & 16 & 68.0 & 25 & 50.0 \\
\hline Male & 34 & 100.0 & 50 & 50.0 \\
\hline Total & 50 & 500.0 \\
\hline
\end{tabular}

Table 3: Incidence of Glaucoma and CDK in cases and controls studied

\begin{tabular}{|l|l|l|l|l|l|}
\hline & \multicolumn{2}{|l|}{$\begin{array}{l}\text { Cases } \\
(\mathrm{n}=50)\end{array}$} & \multicolumn{2}{l}{$\begin{array}{l}\text { Control } \\
(\mathrm{n}=50)\end{array}$} & \multirow{2}{*}{ P value } \\
\cline { 2 - 5 } & No & $\%$ & No & $\%$ & \\
\hline Glaucoma & 19 & 38.0 & 6 & 12.0 & $0.003^{* *}$ \\
\hline CDK & 7 & 14.0 & 2 & 4.0 & $0.081+$ \\
\hline
\end{tabular}

In the above table, PXF is strongly associated with glaucoma $(\mathrm{P}=0.003)$ and significantly associated with Climatic Droplet Keratopathy $(\mathrm{P}=0.081)$. Student $t$ test.

Table 4: Distribution of glaucoma among cases

\begin{tabular}{|c|c|c|c|}
\hline \multirow[t]{2}{*}{ Glaucoma } & \multicolumn{2}{|l|}{ Gender } & \multirow{2}{*}{$\begin{array}{l}\text { Total } \\
(\mathrm{n}=50)\end{array}$} \\
\hline & $\begin{array}{l}\text { Female } \\
(\mathrm{n}=16)\end{array}$ & $\begin{array}{l}\text { Male } \\
(n=34)\end{array}$ & \\
\hline Nil & $9(56.3 \%)$ & $22(64.7 \%)$ & $31(62 \%)$ \\
\hline Yes & $7(43.8 \%)$ & $12(35.3 \%)$ & $19(38 \%)$ \\
\hline Primary open angle glaucoma -both eye & $4(25 \%)$ & $8(23.5 \%)$ & $12(24 \%)$ \\
\hline Glaucoma suspect & $2(12.5 \%)$ & $0(0 \%)$ & $2(4 \%)$ \\
\hline Primary open angle glaucoma-left eye & $0(0 \%)$ & $2(5.9 \%)$ & $2(4 \%)$ \\
\hline Chronic angle closure glaucoma-both eye & $1(6.3 \%)$ & $0(0 \%)$ & $1(2 \%)$ \\
\hline Chronic angle closure glaucoma-right eye & $0(0 \%)$ & $1(2.9 \%)$ & $1(2 \%)$ \\
\hline Ocular hypertension & $0(0 \%)$ & $1(2.9 \%)$ & $1(2 \%)$ \\
\hline
\end{tabular}

Table 5: Distribution of Climatic droplet keratopathy in cases and controls

\begin{tabular}{|l|l|l|l|}
\hline Climatic droplet keratopathy DK & Gender & $\begin{array}{l}\text { Total } \\
(\mathrm{n}=50)\end{array}$ \\
\cline { 2 - 4 } & $\begin{array}{l}\text { Female } \\
(\mathrm{n}=16)\end{array}$ & $\begin{array}{l}\text { Male } \\
(\mathrm{n}=34)\end{array}$ & $28(82.4 \%)$ \\
\hline Nil & $15(93.8 \%)$ & $28(86 \%)$ \\
\hline Yes & $1(6.3 \%)$ & $6(17.6 \%)$ & $7(14 \%)$ \\
\hline Climatic droplet keratopathy DK-Both Eye & $0(0 \%)$ & $4(11.8 \%)$ & $4(8 \%)$ \\
\hline Climatic droplet keratopathy DK-Left Eye & $1(6.3 \%)$ & $1(2.9 \%)$ & $2(4 \%)$ \\
\hline RE-CDK & $0(0 \%)$ & $1(2.9 \%)$ & $1(2 \%)$ \\
\hline
\end{tabular}




\section{Discussion}

The prevalence of exfoliation increases dramatically with age and varies considerably among populations worldwide (9). The true variation in prevalence of exfoliation syndrome is because of different age groups studied, environmental influences, definition of exfoliation syndrome, and examination techniques used. Exfoliation syndrome is more common in older age-groups, occurring in the late $60 \mathrm{~s}$ and early $70 \mathrm{~s}$. The condition may be unilateral or bilateral.

The prevalence rate of PXF syndrome in different populations shows extensive variations-38\% in Navajo Indians (10), 5-25\% in the Scandinavian countries (11), 1.8\% in the Framingham Eye Study (12), and $0 \%$ in Eskimos (11).

In our study study we found that increase in age is significantly associated with pseudoexfoliation $(\mathrm{P}=0.026)$. In our study study, we found no sex predilection, which is also in accordance with other studies (13).

In our study, we found $2 \%$ prevalence of ocular hypertension and $36 \%$ prevalence of glaucomatous optic neuropathy of PXF cases. This is in accordance to Kozart and Yanoff (14), which is a clinical based study with $15 \%$ prevalence of OHT and $7 \%$ prevalence of glaucoma in patients with PXF. Our data is also similar to The Blue Mountains Eye Study (15), which is a population based study with reported prevalence of $9.3 \%$ OHT and $14.2 \%$ glaucoma.

We found a $4 \%$ prevalence of narrow angles in our population with PXF, which is four times the prevalence in our population without PXF. This is in accordance with Layden and Schaffer (7) reported a 23\% prevalence of narrow angles in 100 patients with PXF. Also Wishart et al (8) reported, 9\% to $18 \%$ had angles that were considered to be occludable and $14 \%$ had evidence of angle closure on the basis of peripheral anterior synechiae. In our study we found PXF is strongly associated with glaucoma $(\mathrm{P}=0.003)$ and significantly associated with Climatic Droplet Keratopathy $(\mathrm{P}=0.081)$

As per best of our knowledge, there is no study on the association between PXF with CDK from the Indian subcontinent. In this study, we report the association between PXF with CDK in a rural population in southern India. Forsius et al. (16) (2002) did not find association between pseudoexfoliation and climatic changes like $\mathrm{CDK}$ and pterygium as previously assumed by other investigators. However, further studies are required to find an association between PXF and CDK, considering the environmental factors.

\section{Conclusion}

In this rural population of south India aged 50 years and above, we found that glaucomatous optic neuropathy and CDK occur more frequently in the population with PXF syndrome compared to people without PXF. However further studies are required to support the association between PXF and CDK.

\section{References}

[1]. Ritch R. Exfoliation syndrome: the most common identifiable cause of open-angle glaucoma. J Glaucoma. 1994;3(2):176-177.

[2]. Schlotzer-Schrehardt U, Naumann GOH. Ocular and systemic exfoliation syndrome. Am J Ophthalmol. 2006;141(5):921-937.

[3]. Mitchell P, Wang JJ, Smith W. Association of exfoliation syndrome with increased vascular risk. Am J Ophthalmol. 1997;124(5):685-687.

[4]. Prince AM, Ritch R. Clinical signs of the exfoliation syndrome. Ophthalmology. 1986;93(6):803-807.

[5]. Repo LP, Terasvirta ME, Tuovinen EJ. Generalized peripheral iris transluminance in the exfoliation syndrome. Ophthalmology. 1990;97(8):1027-1029.

[6]. Ritch R. Exfoliation syndrome. In: Ritch R, Shields MB, Krupin T, eds. The glaucomas, 2nd ed. St Louis: Mosby, 1996:993-1022.

[7]. Layden WE, Shaffer RN. Exfoliation syndrome. Am J Ophthalmol 1974;78:835-41.

[8]. Wishart PK, Spaeth GL, Poryzees EM. Anterior chamber angle in exfoliation syndrome. Br J Ophthalmol 1985;69:103-7.

[9]. Ringvold A. Epidemiology of the pseudo-exfoliation syndrome. Acta Ophthalmol Scand. 1999;77(4):371-375

[10]. Faulkener HW. Pseudoexfoliation of the lens among Navajo Indians. Am J Ophthalmol 1971;72:206.

[11]. Forsius H. Prevalence of pseudoexfoliation of the lens in Finns, Lapps, Icelanders, Eskimos and Russians. Trans Ophthalmol Soc UK 1979;99:296.

[12]. Hiller R, Sperduto RD, Krueger DE. Pseudoexfoliation, intraocular pressure, and senile lens changes in a population based survey. Arch Ophthalmol 1982;100:1080-7.

[13]. Lamba PA, Giridhar A. Pseudoexfoliation syndrome (prevalence based on random survey hospital data). Indian J Ophthalmol 1984;32:169-73.

[14]. Kozart DM, Yanoff M. Intraocular pressure status in 100 consecutive patients with exfoliation syndrome. Ophthalmology urban south Indian population. Indian J Ophthalmol 1998;46:81-6.

[15]. $\quad 1982 ; 89: 214-18$

[16]. Mitchell P, Wang JJ, Hourihan F. The relationship between glaucoma and pseudoexfoliation: The Blue Mountains Eye Study. Arch Ophthalmol 117:1319-24.

[17]. Forsius H, Forsman E, Fellman J, Eriksson AW. Exfoliation syndrome: frequency, gender distribution and association with clinically induced alterations of the cornea and conjunctiva. Acta Ophthalmol Scand 2002; $80: 478-484$. 